\title{
Características histopatológicas necessárias para a pesquisa de bacilos álcool-ácido resistentes no eritema nodoso*
}

\author{
Histopathologic finds of research of acid-fast bacilli in erythema \\ nodosum
}

\author{
Mario Cezar Pires, Marli de Jesus Ferreira Calux e Neusa Yuriko Sakai Valente \\ Hospital do Servidor Público Estadual de São Paulo. São Paulo, SP - Brasil
}

\begin{abstract}
Resumo
Através de estudo histopatológico retrospectivo de 51 lâminas de eritema nodoso (EN) comum e 39 lâminas de eritema nodoso hansênico (ENH) comprovou-se que o quadro histopatológico de ambos os grupos diferiu em diversos aspectos. Os achados que mais divergiram entre as duas afecções foram: a presença do infiltrado granulomatoso virchoviano em todos os casos de ENH; a localização predominante do infiltrado inflamatório, dermo-hipodérmica no ENH e hipodérmica no EN comum; o acometimento septal preferencial no EN comum e lobular no ENH; o encontro de células gigantes tipo corpo estranho no EN comum e sua ausência no ENH; o achado predominante de células mononucleares no EN comum e neutrófilos no ENH; a presença de infiltrado inflamatório ao redor de nervos no ENH.

Comprovou-se que a pesquisa de bacilo álcool-ácido resistente (BAAR) não necessita ser realizada em todos os casos de EN, uma vez que ao exame histopatológico de rotina existem diferenças entre o EN comum e o ENH que podem orientar a realização deste procedimento. A pesquisa deve ser realizada quando ao exame de rotina nas lâminas coradas por hematoxilina-eosina forem observadas as características histopatológicas do ENH descritas no estudo.
\end{abstract}

Eritema nodoso, patologia. Hanseníase lepromatosa, patologia.

\begin{abstract}
It was possible to prove, by means of retrospective histopathological studies of 51 glass slides of common erythema nodosum (EN) and 39 glass slides of erythema nodosum leprosum (ENL), that the histopathological features of the two groups differed in several ways. It was found that the most prominent divergent findings between these two diseases was the presence of a lepromatous granulomatous infiltrate in the ENL; the predominant location of the inflammatory infiltrate was derma-hypodermal in ENL and hypodermal in common EN; there was a preferential septa attack in common EN and lobular in ENL; foreign giant cells occurred only in common EN; the lymphocyte cell infiltration in common EN and of neutrophills in ENL and the presence of
\end{abstract}

\footnotetext{
* Resumo de dissertação de mestrado apresentada à Comissão de Pós-Graduação do Hospital do Servidor Público Estadual de São Paulo, em 1993. Correspondência para/Correspondence to: Mario Cezar Pires - Av. Barão da Vitória, 93 - 02552-010 São Paulo, SP - Brasil. Fax: (011) 573-8854. Email: mapire@ibm.net.

Edição subvencionada pela FAPESP. Processo 95/2290-6.

Recebido em 18.12.1995. Reapresentado em 25.4.1996. Aprovado em 17.5.1996.
} 
inflammatory infiltrate around nerves in ENL. Our study has proved that the search for M. leprae does not have to be made in all cases of EN as there are histological differences in the routine histopathological exam between common EN and ENL that can alert to the real need for this procedure. This search must be performed when during the routine histopathological exam of sections stained by hematoxilin-eosin the ENL histopathological caracteristics delineated herein are observed.

Erythema nodosum, pathology. Leprosy, lepromatous, pathology.

\section{INTRODUÇÃO}

A controvérsia a respeito da identidade entre o eritema nodoso hansênico $(\mathrm{ENH})$ e o eritema nodoso (EN) associado a outros fatores tem sido objeto de estudo há mais de $40 \operatorname{anos}^{2,8,15,16,19}$.

Alguns autores ${ }^{8,15}$ consideraram idênticas as características histopatológicas das duas afecções, enquanto outros 2,16,19 julgaram que o ENH diferia histopatologicamente do EN associado a outros fatores. Alguns livros básicos de dermatologia recomendam, inclusive, a pesquisa de bacilo álcool-ácido resistente (BAAR) em todos os casos de EN, independente do quadro histopatológico encontrado com hematoxilina-eosina ${ }^{3,18}$.

$\mathrm{Na}$ literatura consultada foi encontrado apenas um estudo de pequeno número de casos, não submetido à análise estatística, em que se comparou o quadro histopatológico do ENH com o do EN associado a outros fatores, apresentado por Helwig ${ }^{8}$ em 1961, quando mostrou que havia diferenças entre as duas entidades.

Propõe-se, no presente estudo, verificar as alterações constantes nos exames histopatológicos de casos de eritema nodoso associado a diversas causas, comparando-as às encontradas em casos de eritema nodoso hansênico, avaliando-se a necessidade da pesquisa de BAAR em todos os casos de eritema nodoso.

\section{METODOLOGIA}

Foram reestudadas as alterações histopatológicas de 168 lâminas, sendo que destas, 113 estavam arquivadas com o diagnóstico histopatológico de EN associado a outros fatores e 62 com o diagnóstico histopatológico de hanseníase virchoviana reacional.

As lâminas foram obtidas dos arquivos dos serviços de anatomia patológica de cinco hospitais do Estado de São Paulo*.
Foram utilizados os seguintes critérios de inclusão:

- tecido celular subcutâneo representado e com septo interlobular

- coloração de boa qualidade

- presença de no mínimo 3 cortes.

Após revisão inicial foram excluídas algumas lâminas que estavam arquivadas como eritema nodoso e apresentavam características de outras paniculites, tais como peri-arterite nodosa e paniculite eosinofílica ${ }^{1,9}$.

Utilizando os critérios de inclusão e exclusão, foram selecionadas 90 lâminas para serem avaliadas sistematicamente, conforme descrito a seguir, sendo 51 de EN associado a outros fatores e 39 de hanseníase virchoviana reacional.

Foram analisadas as alterações observadas nos cortes corados com hematoxilina-eosina e a pesquisa de BAAR foi realizada pela técnica de Ziehl-Neelsen em todos os casos a partir dos blocos de parafina arquivados. Em alguns casos também foi realizada pesquisa de antígenos micobacterianos com anticorpos anti-BCG, conforme técnica já utilizada por Takahashi ${ }^{20}$.

$\mathrm{Na}$ avaliação das diversas alterações histopatológicas, foram consideradas as seguintes características:

localização predominante do infiltrado inflamatório; localização do infiltrado inflamatório na hipoderme; distribuição do infiltrado inflamatório;

tipo celular predominante no infiltrado inflamatório; presença de células gigantes tipo corpo estranho; presença de necrose tecidual;

presença de granuloma virchoviano;

alterações vasculares;

pesquisa de $M$. leprae.

Os resultados foram submetidos à análise estatística pelos testes do qui-quadrado e exato de Fisher.

\section{RESULTADOS}

Em todos os casos arquivados como EN associado a outros fatores, a pesquisa de BAAR foi negativa $(n=51)$ e em todos os casos de hanseníase virchoviana reacional, esta foi positiva. Em 35 casos

\footnotetext{
* Hospital do Servidor Público Estadual; Hospital das Clínicas da Faculdade de Medicina da Universidade de São Paulo; Complexo Hospitalar Padre Bento de Guarulhos; Santa Casa de Misericórdia de São Paulo e Hospital Ipiranga.
} 
de EN onde se realizou a pesquisa de antígenos micobacterianos com anticorpos anti-BCG, esta foi negativa.

Foram denominados então os casos com pesquisa de BAAR negativa de eritema nodoso comum e os casos com pesquisa de BAAR positiva de eritema nodoso hansênico, nomenclatura já utilizada na literatura por outros autores ${ }^{5,15,17}$.

Dentre as principais alterações encontradas, destacaram-se:

- quando o processo inflamatório localizou-se principalmente no tecido celular subcutâneo (TCSC), a pesquisa de BAAR foi negativa em $88,68 \%$. O acometimento dérmico, quando presente nesses casos, restringiu-se a um leve infiltrado inflamatório linfo-histiocítico perivascular e peri-anexial (Tabela 1).

Tabela 1 - Localização predominante do infliltrado inflamatório na derme e/ou hipoderme nos casos de eritema nodoso com ausência ou presença de BAAR no exame histopatológico.

\begin{tabular}{lcccc}
\hline Localização & Ausência & Presença & Total & $\begin{array}{c}\% \\
\text { Ausência }\end{array}$ \\
\hline Hipoderme & 47 & 6 & 53 & 88,68 \\
Derme & 0 & 25 & 25 & 0,00 \\
Junção DH & 4 & 1 & 5 & 80,00 \\
Derme/Hipoderme & 0 & 5 & 5 & 0,00 \\
Junção DH/Hipo & 2 & 2 & 2 & 0,00 \\
\hline Total & 51 & 39 & 90 & 56,67 \\
\hline
\end{tabular}

Junção $\mathrm{DH}=$ Junção derme-hipoderme.

A análise estatística revelou associação significativa entre infiltrado inflamatório na hipoderme e ausência de BAAR.

- o envolvimento predominantemente do septo de tecido conjuntivo foi associado à pesquisa de BAAR negativa (Tabela 2), enquanto que quando os lóbulos gordurosos estavam preferentemente atingidos pelo processo inflamatório a pesquisa de BAAR foi positiva.

Tabela 2 - Localização predominante do infiltrado inflamatório no tecido celular subcutâneo nos casos de eritema nodoso com ausência ou presença de BAAR no exame histopatológico.

\begin{tabular}{lcccc}
\hline Localização & Ausência & Presença & Total & $\begin{array}{c}\% \\
\text { Ausência }\end{array}$ \\
\hline Septal & 51 & 17 & 68 & 75,00 \\
Lobular & 0 & 13 & 13 & 0,00 \\
Septal/lobular & 0 & 9 & 9 & 0,00 \\
\hline Total & 51 & 39 & 90 & 56,67 \\
\hline
\end{tabular}

Os resultados dispensam análise estatística.

Houve associação significativa entre o envolvimento septal e a ausência de BAAR.

- o infiltrado inflamatório apresentou-se disposto ao redor de vasos sangüíneos e/ou anexos cutâneos em ambos os grupos.
- infiltrado inflamatório ao redor de nervos em 18 de 19 casos onde a pesquisa de BAAR foi positiva, sendo que em alguns destes notou-se agressão de nervos.

- em 91,67\% dos casos em que o tipo celular predominante foi linfomononuclear (LMN), a pesquisa de BAAR foi negativa, enquanto que polimorfonuclear (PMN) neutrófilos foram as células predominantes em 28 de 35 casos de ENH. - células gigantes tipo corpo estranho foram vistas em 9 casos de EN comum e em nenhum dos ENH.

- notou-se necrose tecidual em 10 casos de ENH e em apenas 3 de EN comum.

- a fragmentação nuclear predominou entre os casos de ENH (28 contra 9 de EN comum).

- a presença de infiltrado crônico granulomatoso apareceu somente nos casos de ENH (Tabela 3).

Tabela 3 - Infiltrado granulomatoso virchoviano nos casos de eritema nodoso com ausência ou presença de BAAR no exame histopatológico.

\begin{tabular}{lcrrc}
\hline $\begin{array}{l}\text { Infiltrado } \\
\text { Granulomatoso }\end{array}$ & Ausência & Presença & Total & $\begin{array}{c}\% \\
\text { Ausência }\end{array}$ \\
\hline Regressivo & 0 & 37 & 37 & 0,00 \\
Progressivo & 0 & 2 & 2 & 0,00 \\
\hline Total & 0 & 39 & 39 & 0,00 \\
\hline Os resultados dispensam análise estatística. & & &
\end{tabular}

- vasculite de vasos sangüíneos de pequeno e médio calibre foi notada principalmente nos casos de ENH (pequeno calibre em 13 casos e de médio calibre em 31).

\section{DISCUSSÃO}

$\mathrm{Na}$ análise histopatológica dos 90 casos, primeiramente pode-se destacar que nos casos onde o processo inflamatório localizou-se principalmente no TCSC, a pesquisa de BAAR foi negativa em $88,68 \%$. Além disso, o acometimento dérmico, quando presente, restringiu-se a um leve infiltrado inflamatório linfohistiocítico perivascular e peri-anexial. Por outro lado, quando a derme foi a localização preferencial do infiltrado inflamatório, a pesquisa de BAAR foi sempre positiva. Houve uma associação significante entre a localização do infiltrado inflamatório na hipoderme e a ausência de BAAR (Tabela 1).

Os resultados encontrados no presente estudo mostram claramente que nos casos de EN comum, o processo inflamatório localizou-se principalmente no TCSC, o que está de acordo com a observação e/ou opinião de diversos autores ${ }^{4,7,8,10,11,13}$. No ENH, o infiltrado inflamatório instala-se sobre granuloma 
virchoviano regressivo prévio, podendo assim ocorrer tanto na derme como na hipoderme, conforme já verificado anteriormente ${ }^{2,15,16,17,19,21}$.

Observou-se que o envolvimento predominantemente do septo de tecido conjuntivo foi associado à pesquisa de BAAR negativa (Tabela 2), enquanto que quando os lóbulos gordurosos estavam preferentemente atingidos pelo processo inflamatório a pesquisa de BAAR foi positiva. Nos casos com pesquisa de BAAR positiva, também foram observados vários com infiltrado inflamatório septal, mas em geral os lóbulos gordurosos estavam comprometidos intensamente, isoladamente ou em associação ao envolvimento septal. Houve uma associação significante entre o predomínio de paniculite septal e a ausência de BAAR nos cortes histológicos.

Estes achados estão de acordo com vários autores ${ }^{1,4,7,8,10,11,13}$ que observaram a presença do infiltrado inflamatório septal como característica importante do EN comum.

Portugal ${ }^{15}$, apesar de defender a identidade entre o EN comum e o ENH, também observou o maior envolvimento lobular em seus casos de ENH.

Pode-se afirmar que no EN comum o infiltrado inflamatório tendeu a localizar-se no septo de tecido conjuntivo. No ENH, os lóbulos gordurosos foram acometidos mais freqüentemente do que no EN comum.

O infiltrado inflamatório, tanto nos casos com pesquisa de BAAR negativa, quanto nos casos com pesquisa de BAAR positiva, apresentou-se disposto ao redor de vasos sangüíneos e/ou anexos cutâneos.

A presença do infiltrado inflamatório ao redor de nervos, agredindo-os ou não, diferiu entre os dois grupos. Observou-se infiltrado inflamatório ao redor de nervos em 18 de 19 casos onde a pesquisa de BAAR foi positiva, sendo que em alguns destes notou-se agressão de nervos e em apenas 3 casos de EN comum (sem agressão). Apesar desses resultados serem, numa fria análise estatística, significantes, deve-se ressaltar que na grande maioria das vezes, em ambos os grupos, os nervos não estavam representados ou não foram reconhecidos nos cortes histológicos, o que restringiu a utilização desse parâmetro na distinção entre o EN comum e o ENH.

Em 91,67\% dos casos em que o tipo celular predominante foi LMN, a pesquisa de BAAR foi negativa, enquanto que naqueles com pesquisa de BAAR positiva, essas células estavam presentes em maioria em apenas 4 casos. Os leucócitos PMN neutrófilos, por sua vez, foram as células mais numerosas em 28 de 35 casos com pesquisa de BAAR positiva, sempre associados a um infiltrado virchoviano regressi- vo de base. Nos casos com pesquisa de BAAR negativa, foram encontrados 7 em 51 casos onde o tipo celular mais encontrado no infiltrado inflamatório foram os leucócitos PMN neutrófilos, sendo que em três destes casos foi encontrado vasculite, enquanto que nos restantes os leucócitos PMN neutrófilos estavam presentes nos septos interlobulares. A análise estatística revelou que o predomínio de LMN está associado à ausência de bacilos na pesquisa de BAAR

No EN comum tem sido descrito que nas fases iniciais do processo há maior número de PMN neutrófilos, que com a evolução são substituídos por

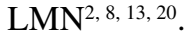

Quanto ao ENH, vários autores ${ }^{3,4,5,15,16,21}$ afirmaram que o infiltrado inflamatório seria composto por PMN neutrófilos principalmente, e alguns citaram inclusive a presença de microabcessos ${ }^{17}$.

Houve uma associação significante entre a presença de células gigantes multinucleadas tipo corpo estranho e a ausência de bacilos na pesquisa de BAAR ( 9 casos). Estas células não foram vistas em nenhum caso de ENH. Este achado está de acordo com os de Helwig ${ }^{8}$, que sugeriu que o encontro destas células seria indicativo de EN comum.

Existiu uma relação entre a presença de necrose tecidual, comprometendo a epiderme, a parede de vasos sangüíneos, o septo de tecido conjuntivo ou os lóbulos gordurosos, e a presença de BAAR.

Mehregan ${ }^{11}$ colocou como um dos critérios de exclusão do diagnóstico de EN comum a presença de necrose tecidual, enquanto que Cockerell ${ }^{6}$ considerou a possibilidade da existência de necrose de lipócitos em casos mais crônicos de EN comum.

No ENH, vários autores assinalaram a presença de edema ${ }^{4,21}$, degeneração ${ }^{17}$ ou de necrose fibrinóide de tecido conjuntivo nos casos de ENH.

Este estudo vem corroborar a opinião de Mehregan ${ }^{11}$, indicando a ausência de áreas importantes de necrose em casos de EN comum, excetuando-se a pequena frequiência de casos com vasculite aguda.

A pesquisa de BAAR foi positiva em 28 casos com presença de fragmentação nuclear, sempre em associação com um infiltrado granulomatoso virchoviano, tanto na hipoderme (septos fibrosos e lóbulos gordurosos), como na derme. Fragmentação nuclear foi um achado raro nos casos de EN comum. Houve uma associação negativa entre a fragmentação nuclear e a ausência de BAAR.

Fragmentação nuclear na parede de vasos sangüíneos foi um achado considerado importante nos casos agudos de EN comum, por autores como 
Winkelmann e Forstrom ${ }^{21}$. No ENH, por outro lado, a fragmentação nuclear foi citada tanto em casos com características agudas como associada a alterações mais crônicas ${ }^{4,8,19,21}$. No presente estudo, o que chamou a atenção e pareceu diferenciar o EN comum do ENH foi a presença de fragmentação nuclear associada ao infiltrado virchoviano de base no último.

Em todos os casos onde observou-se a presença de infiltrado granulomatoso virchoviano, a pesquisa de BAAR foi positiva, com aparência regressiva em 37 e progressiva em 2 casos. Esta alteração não apareceu em nenhum caso com pesquisa de BAAR negativa (Tabela 3 ).

$\mathrm{Na}$ literatura do ENH, diversos autores ${ }^{4,5,8,15,16,17}$ afirmaram que o infiltrado granulomatoso virchoviano estaria presente em todas as lesões de ENH. Até mesmo Portugal e col. ${ }^{15}$ e Azulay $^{2}$, que afirmavam a total identidade entre o EN comum e o ENH, observaram a presença do granuloma virchoviano no $\mathrm{ENH}$, dado este que seria o suficiente para diferenciálo do EN comum. Enfatiza-se que a presença desta alteração pareceu decisiva na diferenciação entre o EN comum e o ENH, fato este já destacado por Rath de Souza ${ }^{19}$.

Nos vasos sangüíneos tanto de pequeno calibre como de médio calibre houve associação significante entre alterações consideradas inespecíficas e o EN comum. Vasculite foi um achado comum nos casos com pesquisa de BAAR positiva, sendo que em alguns casos havia vasculite granulomatosa ou residual em vasos sangüíneos de médio calibre.

A observação de alterações vasculares no EN comum, é bastante controvertida na literatura. Alguns autores ${ }^{21}$ consideraram as alterações vasculares importantes no EN comum, sendo inclusive primárias no processo. No entanto, a maioria dos auto-

\section{REFERÊNCIAS BIBLIOGRÁFICAS}

1. ACKERMAN, A.B. Panniculitis. In: Ackerman, A.B. Histologic diagnosis of inflammatory skin diseases. Philadelphia, Lea \& Febiger, 1988b. p. 784-90.

2. AZULAY, R.D. Comentários. Bol. Serv. Nac. Lepra, 15 (n esp):95, $1956 b$.

3. AZULAY, R.D. \& AZULAY, D.R. Eritema nodoso. In: Dermatologia. 2 ed. Rio de Janeiro, Guanabara-Koogan, 1992. p. 52.

4. BASTAZINI, I. Contribuição ao estudo da reação hansênica. Botucatu, 1973. [Tese de Doutorado - Faculdade de Medicina da Universidade de São Paulo].

5. CAMPOS, N.S. Patologia geral do eritema nodoso. Bol. Serv. Nac. Lepra, 15 (nº esp):41-5, 1956. $\operatorname{res}^{6,7,8,13}$ acredita que as alterações vasculares são inespecíficas e limitadas.

No ENH alterações vasculares foram citadas pela maioria dos autores ${ }^{2,3,4,16,17,19}$. Bastazini ${ }^{4}$ descreveu diversas alterações vasculares, entre as quais a infiltração das camadas média e íntima de veias de maior calibre por histiócitos espumosos, o que caracterizava a vasculite hansênica granulomatosa.

$\mathrm{O}$ granuloma radiado de Miesher ${ }^{12}$ foi considerado um achado raro por diversos autores mesmo em casos de EN comum. Sua presença no ENH foi objeto de grande polêmica na literatura consultada. Portugal $^{16}$ e Azulay ${ }^{2}$, descreveram o encontro do granuloma radiado de Miesher no ENH e por isso afirmaram a identidade entre este e o EN comum. Vários autores contestaram esta opinião $0^{5,16,19}$.

No presente trabalho a presença do granuloma radiado de Miesher não foi considerada, em primeiro lugar pela controvérsia a respeito de sua real existência e em segundo lugar pela raridade do seu achado, fato destacado por Nubé ${ }^{14}$ e Zabel $^{22}$.

Várias diferenças histopatológicas entre o EN comum e o ENH foram observados no presente estudo. Diante destes resultados e com os dados obtidos na revisão de literatura, pode-se afirmar que a pesquisa de BAAR não é necessária em todos os casos com diagnóstico clínico de EN. Esta pesquisa é imprescindível quando a análise da lâmina corada com hematoxilina-eosina apresentar as características aqui descritas como sugestivas de ENH, principalmente a presença do granuloma virchoviano de base, a localização predominantemente dérmica do infiltrado inflamatório, o acometimento lobular importante do TCSC, as alterações vasculares do tipo vasculite granulomatosa ou residual, a agressão a nervos e a presença de leucócitos PMN neutrófilos com leucocitoclasia ou quando houver dúvida clínica.

6. COCKERELL, C.J. Biology and pathophysiology of panniculus adiposus. In: Cockerell, C.J. Pathophysiology of dermatologic diseases. 2nd ed. New York, McGraw-Hill, 1991. p. 383-6.

7. FAVOUR, C.B. \& SOSMAN, M.C. Erythema nodosum. Arch. Int. Med., 80: 435-53, 1947.

8. HELWIG, E.B. Identity of erythema nodosum leprosum. In: Transactions of the symposium on research in leprosy. Baltimore, 1961. p. 28-30.

9. LEVER, W.F. \& SCHAUMBURG-LEVER, G. Inflammatory diseases of the subcutaneous fat. In: Lever, W.F. \& Schaumburg-Lever, G. Histopathology of the skin. 7th ed. Philadelphia, J B Lippincott, 1991b. p. 244-5. 
10. LOEFGREN, S. \& WAHLGREN, F. On the histo-pathology of erythema nodosum. Acta Derm. Venereol., 29: 1-131,1949.

11. MEHREGAN, A.H. Subcutaneous inflammatory panniculitis. ,In: Mehregan, A.H. Pinkus' guide of dermatohistopathology. 4th ed. Norwalk, Appleton Century Crofts, 1986b. p. 262.

12. MIESHER, G. Zur histologie des erythema nodosum. Acta Derm. Venereol. 27:447-68, 1947.

13. MSHANA, R.N.; BELEHU, A.; STONER, G.L.; HARBOE, M.; HAREGEWDIN, A. Demonstration of mycobacterial antigens in leprosy tissues. Int. J. Lepr., 50: 1-19, 1982.

14. NUBÉ, M.J. Miescher's granuloma in erythema nodosum. Dermatologica, 101: 80-4, 1950.

15. PORTUGAL, H. Estrutura histológica, outros dados laboratoriais, bacterioscopia. Bol. Serv. Nac. Lepra, 15 (n ${ }^{\circ}$ esp):16-22, 1956.

16. RAMOS E SILVA, J. Eritema nodoso na Lepra. Bol. Serv. Nac. Lepra, 15 (n $\mathrm{n}^{\circ}$ esp): 5-8, 1956.
17. RIDLEY, D.S. \& JOB, C.K. The pathology of leprosy. In: Ridlay, D.S. \& Job, C.K. Hastings. New York, Churchill Livingstone, 1985. p. 114-27.

18. SAMPAIO, S.A.P.; CASTRO, R.M.; RIVITTI, E.A. Eritema nodoso. In: Dermatologia Básica. 3 ed. São Paulo, Artes Médicas, 1983. p. 123-4.

19. SOUZA, P. R. de. Estrutura histológica, outros dados laboratoriais, bacterioscopia. Bol. Serv. Nac. Lepra, 15 ( ${ }^{\circ}$ esp): 26-9, 1956

20. TAKAHASHI, M.D.F. Hanseníase indeterminada: evolução clínico-patológica. 1989. 107 p. [Tese de Doutorado - Faculdade de Medicina da Universidade de São Paulo].

21. WINKELMAN, R.K. \& FORSTRON, L. New observations in the histopathology of erythema nodosum. J. Invest. Dermatol., 65: 441-6, 1975.

22. ZABEL, M. Zur histopathologie des erythema nodosum. Z Hautkr, 52: 1253-8, 1977. 